\title{
European Journal of Criminology
}

Correlates of war? Towards an understanding of nativity-based variation in immigrant offending

Amber L. Beckley

European Journal of Criminology 2013 10: 408

DOI: $10.1177 / 1477370812470902$

The online version of this article can be found at:

http://euc.sagepub.com/content/10/4/408

Published by:

(9)SAGE

http://www.sagepublications.com

On behalf of:

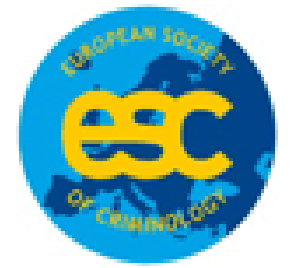

European Society of Criminology

Additional services and information for European Journal of Criminology can be found at:

Email Alerts: http://euc.sagepub.com/cgi/alerts

Subscriptions: http://euc.sagepub.com/subscriptions

Reprints: http://www.sagepub.com/journalsReprints.nav

Permissions: http://www.sagepub.com/journalsPermissions.nav

Citations: http://euc.sagepub.com/content/10/4/408.refs.html 
>> Version of Record - Jun 28, 2013

What is This? 


\title{
Correlates of war? Towards an understanding of nativity- based variation in immigrant offending
}

European Journal of Criminology 10(4) 408-423

(C) The Author(s) 2013

Reprints and permissions: sagepub.co.uk/journalsPermissions.nav DOI: I0.1 I77/|4773708I 2470902 euc.sagepub.com

๑SAGE

\section{Amber L. Beckley}

Stockholm University, Sweden

\begin{abstract}
This study uses Swedish register data to assess the impact of war in the home country on the individual likelihood of registered violent crime among young male immigrants in Stockholm, Sweden. War in the home country during a migrant's residence is significantly related to a higher likelihood of registration for a violent crime. However, these results were not sustained in a sensitivity analysis, which considered serious property crime. Analysis of the history of war in the home country produces effects opposite to those predicted, with more years of war reducing the likelihood of violent crime. These findings indicate that war is capturing other factors, within the home or the receiving country, that may be related to violent crime.
\end{abstract}

\section{Keywords}

Correlates of war, immigrant crime, nativity effect

Whereas some immigrant groups are touted as 'model minorities' owing to their relatively low rates of offending, others seem to offend at especially high rates. Where available, crime statistics from West European countries show a conspicuous overrepresentation of people from war-torn regions (Albrecht, 1997; Martens and Holmberg, 2005; Skardhamar et al., 2011). This pattern has not gone unnoticed by the media and criminal justice officials. ${ }^{1}$ An article from the BBC (BBC News, 2007) headlined 'Young immigrants from violent and war-torn countries are fuelling mayhem and murder on London's streets' implied a conditioning towards violence as a result of being from countries run by warlords. The Telegraph (Hope and Edwards, 2008) reported that refugees were

\section{Corresponding author:}

Amber L. Beckley, Department of Criminology, Stockholm University, SE-106 91 Stockholm, Sweden.

Email: amber.beckley@criminology.su.se 
traumatized in their home country and resorting to crime in Britain. Research from Sweden's National Council of Crime Prevention also notes that traumatic experiences in the home country may result in adjustment problems that lead to crime (Martens and Holmberg, 2005).

Some research evidence connects war exposure to aggression, which, in turn, may be connected to violent offending (Farrington, 1978, 1991; Moffitt, 1993; Nagin and Tremblay, 1999; Sampson and Laub, 1993; Tremblay et al., 2004). Other research has implied a connection between a history of war in the native country and a violent culture that immigrants bring with them. Yet it is questionable whether generalizing that simply coming from a country where there is, or has been, war is related to an increased likelihood of committing crime. Individuals may differ in their experiences of and exposure to war in their home country, which would make such generalizations inappropriate. Since countries generally contain many cultures, assuming a country-wide culture of violence is presumptuous as well. Indeed, the idea of violence as a cultural trait has also been questioned by researchers.

This research provides empirical evidence on whether generalizations about a proclivity towards violent offending among immigrants from war-torn countries are justifiable. It broadens research evidence on immigrant offending by considering the effect of the home country using a large, population-based dataset from Stockholm, Sweden. Stockholm is an excellent location for this research because of its many immigrants from a wide variety of countries. Moreover, research has indicated a relatively high rate of crime among immigrants (Martens, 1997; Martens and Holmberg, 2005). Sweden also provides fairly generous general and specific assistance to immigrants, which may help mitigate nativity-based patterns of poverty found in other countries.

\section{The war-aggression link}

There are two primary factors connecting war in the home country to an aggressionbased higher likelihood of offending. The first is the likelihood that a migrant was exposed to war trauma. International research and theory note that direct exposure to war plays an important role in levels of aggression and negative outcomes (Macksoud et al., 1993: 628-9; Sagi-Schwartz et al., 2008; Shaw, 2003). The second key factor is the likelihood of the war trauma exposure actually leading to negative outcomes. Although adverse psychological outcomes appear to be the most common (Barenbaum et al., 2004: 44), resilience can also result (Cairns, 1996; King et al., 1999; Punamäki, 1996; Yule, 2000). Some research from Sweden provides an indication of the prevalence of these factors.

In a series of Swedish studies by Almqvist and colleagues (Almqvist and BrandellForsberg, 1997; Almqvist and Broberg, 1999; Almqvist and Hwang, 1999), approximately 84 percent of a small group $(n=42)$ of Iranian refugee children had been directly exposed to violence. The children were between 10 months and 4 years of age when they experienced war trauma and were initially assessed one year after their arrival in Sweden; 40 percent of the children were reported by parents to display aggressive behaviour in the initial investigation. In the follow-up study, conducted two-and-a-half years after the initial assessment, aggressiveness was the symptom most frequently reported by parents, with 38 percent of the remaining children $(n=34)$ reported to display such behaviour. 
Another series of Swedish studies (Hjern and Angel, 2000; Hjern et al., 1991; Hjern et al., 1998) considered a sample of 63 children aged 2 to 15 who came to Stockholm from Chile, Lebanon, Turkey and Iran between 1986 and 1987. Approximately twothirds of the children had been exposed to war or persecution prior to migration. Parents' reports of defiance and aggression and teachers' reports of deviant behaviour in the classroom were most prevalent (approximately 32 percent of 50 children) at the second follow-up, 17 to 19 months after arrival. The six-year follow-up, which included 49 respondents, showed marked decreases in these measures, with 18 percent of the remaining 30 school-aged children still being reported as being deviant in the classroom.

Some research shows a moderate strength correlation between post-traumatic stress disorder (PTSD) and aggression, and war as a significant source of PTSD (Orth and Wieland, 2006). There seems to be little research, however, connecting all three of these factors. In a study on a sample of 98 displaced adult Kosovar Albanians who arrived in Sweden in 1999, 51 percent were reported to have experienced torture (Ekblad et al., 2002). Their scores on an aggression index fell in the middle range between approximately 50 and 58 percent. The authors also noted that mass displacement, which may not be experienced by all immigrants from war-torn countries, may have been an additional source of trauma.

Altogether these studies indicate a moderate to high level of exposure to trauma and a low to moderate prevalence of aggression among Swedish immigrants. Yet the samples were relatively small and it is difficult to say whether these same figures would be found in larger samples more representative of the immigrant population. There is also some indication that post-war aggression dissipates with time. In summary, it may be an overgeneralization to assert that immigrants from a war-torn country will be aggressive and, therefore, likely to commit violent crime.

\section{War and a culture of violence}

War in the home country could lead to, or even be generated by, commonly held attitudes and values favourable to violence. Archer and Gartner (1976) found support for the idea that war redefines violence as an acceptable means of individual-level problem solving. Sipes (1973), on the other hand, argues that aggression is a socially learned behaviour of which war and individual-level violence are both symptoms. There are no clear roots to this aggression and, as Sampson and Bean (2006: 23) note, the violent culture appears to have a 'life of its own'. Regardless of whether war precedes individual violence or is a symptom of a greater predisposition towards aggression, the use of violence becomes inherent to the individual and will persist in new environments. The view of a persistent, portable immigrant culture is not new to immigration studies, though the immigrant culture is usually viewed as a positive influence (Morenoff and Astor, 2006; Portes and Zhou, 1993; Thomas and Znaniecki, 1918).

Miguel and colleagues (2008) assessed the connection between war and violence as a cultural value through a novel approach of looking at on-field violence by soccer players. They operationalized the player's birth country as his team country. The authors argued that this weakness was unproblematic because many players from countries with a long 
history of war played on the teams of relatively peaceful countries, resulting in a potential underestimation of the effect of a history of war. They estimated the relationship between the number of years of civil war in the player's team country, up to 45 years in the past, and his number of violent incidents while on field. The results showed that a player's likelihood of on-field violence increases along with the number of years of civil war in the team country. The authors argued that their results provide evidence of a link between war and a violent culture.

Researchers, however, are challenging the perspective that culture consists of a static set of values in favour of viewing 'culture in action' (Berry, 1997; Byrne and Stowell, 2007; Kirk and Papachristos, 2011; Sampson and Bean, 2006; Swidler, 1986). From a culture in action perspective, violence may be a tool used to solve problems rather than a permanent mind-set. For example, if war eliminates the opportunity for state-sanctioned conflict resolution, an individual may turn to violence to resolve conflicts. After the individual migrates to a peaceful country, where non-violent means of conflict resolution are available, the use of violence becomes unnecessary. Swidler (1986) argues that culture actually works to shape action and make new behaviour possible. Some research has supported the idea that pre-immigration attitudes and behaviours are subject to change (Black, 1987; White et al., 2008). Yet, even if attitudes cannot change, Luckenbill and Doyle (1989) point out that arguments behind the idea of cultural roots of crime often lack empirical support.

Both of the perspectives of the potential effect of a home-country war on receivingcountry offending appear to face empirical and theoretical challenges. The primary concern for the war-aggression link is whether past findings based on small samples with high proportions of direct war exposure can be generalized to everyone coming from the same country, without regard for the level of war exposure. For the culture of violence argument, the empirical concern is straightforward: does a history of war in the home country affect levels of post-migration offending? There are, thus, two hypotheses on which to base an empirical test of whether the presumed associations hold.

H1: The average migrant who was present during a war in the home country is more likely to be registered for a violent crime than the average migrant who was not present during a war in the home country.

H2: On average, a lengthier history of war in a migrant's home country is related to a greater likelihood of a recorded violent crime.

\section{Data and method}

I use official data on foreign-born males, aged 16 and older, from 10 cohorts, 1975-84, living in Stockholm, Sweden, between 1996 and 2003 - a total of approximately 26,000 individuals ranging in age from 16 to 28 years. The sample was extracted from the Stockholm Area Metropolitan Dataset (SAMD), a Stockholm-based set of register data collected by the Swedish government. The data are in panel format, with the person-year as the unit of analysis. These data were merged with data from the Swedish police, the UCDP/PRIO Armed Conflict Dataset version 4-2009 (Gleditsch et al., 2002), and data from the United Nations. 


\section{Measures}

Dependent variable: Violent crime. The dependent variable of violent offending is measured as the occurrence of at least one registration as a suspect for a violent crime, measured at the person-year. This variable is dichotomous because very few people had more than one registration for a violent crime per year. Registration as a suspect is the Swedish equivalent of an arrest, but the suspect need not be taken into custody. Violent offences include: homicide, rape, robbery and aggravated assault. Violent offences are distinguished from both non-violent and other minor offences (for example, burglary, larceny, vandalism). Less than 1 percent of the observations were from individuals who may have been incarcerated over the period of study. This was ignored because some prisons in Sweden are open prisons where the individual is not confined to the facility and is still able to offend. Moreover, the data on incarceration come from court sentencing records and no information on early release is included. Any bias incurred by ignoring possible incapacitation is estimated to be minimal.

Independent variables: War. Information on the key independent variable of war or conflict in the home country was obtained from the UCDP/PRIO Armed Conflict Dataset version 4-2009 (Gleditsch et al., 2002). These data comprise information on internal and external conflicts between 1946 and 2008. A conflict is defined as 'a contested incompatibility that concerns government and/or territory where the use of armed force between two parties, of which at least one is the government of a state, results in at least 25 battlerelated deaths' (Harbom et al., 2009: 1). The first measure of war (War 1) indicates whether or not the person was present in the home country during a war. This measure is directed towards the first hypothesis. This measure is stable across the individual. The second measure of war (War 2) denotes a history of war and is measured as the number of years of war in the individual's home country between 1946 and 1975, before anyone in the sample was born. This measure aims to test the second hypothesis related to a possible cultural transmission of violent tendencies. This measure is stable across the country.

Control variables. Human development is used to gauge general sociostructural differences between sending countries. The UN's Human Development Index (HDI), pre2011, is a composite score calculated from a country's adult literacy rate, the school enrolment ratio, average life expectancy at birth and per capita gross domestic product. It is measured every five years. Hastings (2009) noted that many countries were excluded from the UN HDI, along with some data discrepancies. He subsequently recalculated human development and added an additional 53 economies to the UN dataset, working backwards from 2008 to 1975 where possible. His figures are used in the present analysis. The HDI variable is the home-country HDI at the individual's time of emigration. This measure is stable across the individual. As the original metric of the HDI is from 0 to 1 , all scores were multiplied by 10 .

An initial exploration of the data revealed that many HDI scores were still missing for the periods prior to 2008. Four countries accounted for 85 percent of the missing HDI scores: Iraq, Somalia, Poland and Lebanon. For these four countries, missing HDI scores 
have been replaced with the difference of the latest available period and the average change in the HDI (an increase of 0.2 every five years).

Many time-varying variables from the SAMD were included to capture some of the well-known correlates of criminal offending. These are: age in years, education (not enrolled or missing education is the reference category), the home family situation (single with no children is the reference category), and annual disposable income as calculated from family income, measured in SEK10,000 increments. ${ }^{2}$ The number of years spent in Sweden is included to control for both acculturative processes and risk exposure. A dummy variable for the home country was also included to capture other unmeasured effects that the country of origin may have.

\section{Analytic strategy}

Because the data are composed of repeated measures of individuals over time, the withinperson correlation must be accounted for to avoid biased standard errors and inefficient estimates. Yet the research questions are targeted at finding out whether broad statements about immigrants coming from war-torn or less developed countries are justified, not how a change in those factors would affect an individual's likelihood of offending. The hypotheses also predict average effects. The dependence of the observations is, therefore, more of a nuisance than something that should be explicitly modelled. Using generalized estimating equations (GEEs) or population averaged models (Liang and Zeger, 1986; Zeger and Liang, 1986) is appropriate in such cases. Owing to the dichotomous nature of the dependent variable, I use the logit link. GEE estimates are interpreted in the same fashion as regular logit models: they represent the effect of a one-unit change in the covariates on the logit scale and can be transformed into odds ratios. The QIC (quasi-likelihood under the independence model criterion) value (Pan, 2001) is a measure of model fit adapted from the Akaike Information Criterion for GEE models. I proceed with descriptive results, followed by results of simple $t$-tests and, finally, the GEE model results.

As a robustness check, I also conduct a sensitivity analysis that considers the outcome of serious property crime. This includes attempted or completed burglary, or theft via breaking and entering; theft of a motorized vehicle; and firearm theft. Loeber and Farrington (2000) assert that these types of crime and violent crime share risk factors, aggression being one of many. They also place these types of serious property crime and violent crime at endpoints on similar trajectories of offending. In addition, other research on refugee outcomes (Rousseau et al., 1999) specifically combines burglary and physical violence in an index of risk behaviour.

\section{Results}

On average, each individual contributes approximately five observations to the dataset, for a total of 140,927 observations over 26,071 individuals. The individuals come from 170 different countries. Approximately 50 percent of the individuals are from 10 different locations: Iran, Turkey, Iraq, Chile, Finland, Former Yugoslavia, Lebanon, Poland, Somalia and the United States. Approximately 1.5 percent of person-years have 
Table I. Descriptive statistics: Time-varying variables.

\begin{tabular}{|c|c|c|c|c|c|}
\hline Variable & & & Minimum & Maximum & $\begin{array}{l}\text { No. of } \\
\text { observations }\end{array}$ \\
\hline Dependent variables & Percent & & & & \\
\hline Violent crime registration & 1.54 & & 0 & I & 140,927 \\
\hline Serious property crime & & & 0 & I & 140,927 \\
\hline Control variables & Mean & SD & & & \\
\hline Age (centred at 16 years old) & 5.50 & 3.19 & 0 & 12 & 140,927 \\
\hline $\mathrm{Age}^{2}$ & 40.43 & 37.76 & 0 & 144 & 140,927 \\
\hline $\begin{array}{l}\text { Disposable income calculated from } \\
\text { family income }\end{array}$ & 7.83 & 4.95 & 0 & 26.05 & 140,927 \\
\hline \multirow[t]{2}{*}{ Years in Sweden } & 9.98 & 6.92 & 0 & 28 & 140,927 \\
\hline & Percent & & & & \\
\hline In high school & 26.34 & & 0 & I & 140,927 \\
\hline After high school & 11.83 & & 0 & I & 140,927 \\
\hline Before high school & 0.01 & & 0 & I & 140,927 \\
\hline Unemployed job training & 0.21 & & 0 & I & 140,927 \\
\hline Other type of education & 0.84 & & 0 & I & 140,927 \\
\hline $\begin{array}{l}\text { Missing education information or not } \\
\text { enrolled (reference) }\end{array}$ & 60.77 & & 0 & 1 & 140,927 \\
\hline Individual in a marriage or partnership & 7.14 & & 0 & I & 140,927 \\
\hline $\begin{array}{l}\text { Child of one parent in two-parent } \\
\text { home }\end{array}$ & 4.99 & & 0 & 1 & 140,927 \\
\hline Child of single father & 3.13 & & 0 & I & 140,927 \\
\hline Child of single mother & 15.52 & & 0 & I & 140,927 \\
\hline $\begin{array}{l}\text { Individual married/partnership with } \\
\text { children }\end{array}$ & 1.54 & & 0 & 1 & 140,927 \\
\hline Individual is single father & 0.13 & & 0 & I & 140,927 \\
\hline $\begin{array}{l}\text { Child of both parents in two-parent } \\
\text { home }\end{array}$ & 27.09 & & 0 & I & 140,927 \\
\hline Other type of child to single parent & 0.25 & & 0 & I & 140,927 \\
\hline $\begin{array}{l}\text { Individual is single with no children } \\
\text { (reference) }\end{array}$ & 40.20 & & 0 & I & 140,927 \\
\hline
\end{tabular}

a registration for a violent crime (see Table 1). Few individuals, about 6 percent, are registered as violent offenders for more than one year. Just over one-half of the individuals were present in their home country during a war (War 1) (see Table 2). The average individual comes from a country with 3.5 years of war in its history. Table 3 displays the frequency and mean of years at war between 1946 and 1975 by country. The majority of countries had no wars during the 29-year span and the by-country mean number of wars is 2.6. This means that the sample contains an overrepresentation of males from countries with more wars in their history.

Initial $t$-tests of the first hypothesis, without any control variables included, show a significantly higher proportion of registered violent offenders among individuals who 
Table 2. Descriptive statistics: Time-invariant variables.

\begin{tabular}{llllll}
\hline Variable & Percent & & Minimum & Maximum & $\begin{array}{l}\text { No. of } \\
\text { individuals }\end{array}$ \\
\hline $\begin{array}{l}\text { Independent variables } \\
\text { War I }\end{array}$ & 54.09 & & 0 & 1 & 25,928 \\
& $\begin{array}{l}\text { Mean } \\
\text { War 2 }\end{array}$ & SD & & & \\
$\begin{array}{l}\text { Control variable } \\
\text { Home-country HDI at migration }\end{array}$ & 6.52 & 5.30 & 0 & 29 & 26,008 \\
\hline
\end{tabular}

Table 3. Frequency and mean of years of war at the country level between 1946 and 1975 .

\begin{tabular}{lcr}
\hline Years of war & Number of countries & Percent \\
\hline 0 & 105 & 61.40 \\
1 & 18 & 10.53 \\
2 & 6 & 3.51 \\
3 & 5 & 2.92 \\
4 & 5 & 2.92 \\
5 & 7 & 4.09 \\
6 or more & 25 & 14.57 \\
Mean $=2.59$ & & \\
\hline
\end{tabular}

were present in their home country during a war (1.8 percent) compared to those who were not (1.2 percent; $t=-9.40, \mathrm{df}=140,621, p<.000)$. In support of the second hypothesis, the mean number of years of war in the home country prior to 1975 is significantly higher for registered violent offenders (3.8 years) compared with non-offenders (3.5 years; $t=-2.56, \mathrm{df}=140,925, p<.005)$.

The more rigorous GEE models show whether these results persist when control variables are included. Earlier versions of these models (not shown) had 'separation' problems with some country dummy variables because of there being no registered offenders from the given country. For these countries the outcome was perfectly predicted by the dummy variable and all of the observations from the given country were dropped from the analysis. To retain the observations, these country dummies were removed from the models. The earlier models also showed that some of the country coefficients had extreme magnitudes, indicating overfitting. To remedy this problem, a country dummy was included only when there were 100 or more observations from the given country. The models therefore contain only 72 country dummy variables. This makes the results of the country coefficients difficult to interpret; however, they are not shown owing to confidentiality restrictions. All other control variables are also included in all GEE models.

Model 1 tests the first hypothesis that being present in the home country during a war will result in a greater likelihood of a registered violent offence. The results show that 
Table 4. Registration for crime: Odds ratios from GEEs.

\begin{tabular}{llllll}
\hline Variable & Model I & Model 2 & Model 3 & Model 4 & $\begin{array}{l}\text { Sensitivity } \\
\text { analysis }\end{array}$ \\
\hline WAR I & I.35** $(0.1612)$ & & & $1.34^{* *}(0.1615)$ & $0.89(0.1283)$ \\
WAR 2 & & $0.90^{*}(0.0449)$ & & & \\
I war & & $0.92(0.6898)$ & $0.92(0.6900)$ & $1.07(0.8448)$ \\
2-5 wars & & $2.70(1.7099)$ & $2.66(1.6965)$ & $1.13(0.8605)$ \\
6+ wars & & & $0.17^{* *}(0.1044)$ & $0.16^{* *}(0.0992)$ & $0.16^{*}(0.1687)$ \\
QIC & 20437.101 & 20437.804 & 20411.141 & 20401.905 & $n / a$ \\
$n$ & 134,230 & 134,230 & 134,230 & 134,230 & 134,230 \\
\hline
\end{tabular}

Notes: Robust errors in parentheses. Control variables included in all models.

One-tailed $p$-values: $* p<.05 ; * * p<.01$.

War 1 - presence in the home country during a war - has a positive, significant effect on the likelihood of a registered violent offence (see Table 4).

Model 2 tests the effect of a history of war in the home country, War 2. The results show a significant, negative relationship of War 2 to recorded violent crime. This result is contradictory to theory and the opposite of the hypothesized result. Because this could indicate some problems with the continuous variable, I tested War 2 as a categorical variable with the categories of no history of war in the home country (reference), one year of war in the country's history, two to five years of war in the country's history, and six or more years of war in the country's history. The results of this model, Model 3, show that the significant, negative result of Model 2 was driven by a drastically lower likelihood of registration for a violent crime among those who come from countries with six or more wars. Again, this result contradicts theoretical assumptions about the effects of war in the home country and provides a slightly worse model fit. The best-fitting model is Model 4, which contains both the categorical history of war variable and presence in the home country during a war (War 1); the full model results are contained in Appendix 1.

The other country-related variable that was significant in the final model is the HDI variable (this held for categorical as well as continuous measures of HDI, though the continuous measure provided a better fit). ${ }^{3}$ The results show that, on average, immigrants coming from the least developed countries are five times more likely to be registered for a violent offence than those coming from the most developed countries. Income, age, the number of years spent in Sweden, measures of education and family situation are also important within-Sweden covariates. Though not shown, fewer than half of the country dummy variables included in the analysis achieved a two-tailed significance of less than .10; of these, none of the odds ratios exceed 5. Yet there was a tendency for countries with fewer observations to be associated with a stronger effect. This implies that a small amount of overfitting remains. Results of previous Swedish studies support this assumption (Martens and Holmberg, 2005).

Sensitivity analysis. Approximately the same proportion of offenders committed a serious property crime as committed a violent crime, further supporting the idea that this is an extreme type of criminal behaviour. About 20 percent of individuals who were registered 
for serious property crime were also registered for a violent offence, as defined above. The results of the analysis yielded negative, non-significant results for the War 1 variable and results similar to Models 3 and 4 for the categorical War 2 variable (see Table 4). Variants of the serious property crime outcome were analysed and yielded similar results.

\section{Discussion}

The descriptive results show that over half of the individuals had experienced a war in their home country. Initial mean difference tests of the first hypothesis indicate that being present during a war in the home country is significantly related to a greater likelihood of registration for a violent crime. This result persists throughout the more rigorous GEE models, with those who were present during a war in the home country being approximately 35 percent more likely to be registered for a violent offence. Media reports of higher levels of crime among people from war-torn countries are, thus, not entirely baseless. This finding, however, is likely to be inaccurate for both theoretical and empirical reasons.

First, on a country level, war can mean many different things. In extreme cases, war may entail a disruption of public services (including electricity), food shortages, economic crises and widespread violence. These effects have been observed in some of the main countries of origin where there has been widespread war (for example, Iran, Iraq, Former Yugoslavia, Lebanon and Somalia). However, in some countries, Turkey for example, wars are constrained to specific areas, the country continues operating relatively smoothly, and daily life is generally uninterrupted outside of the war zone. These differences are problematic for trauma-related explanations of offending because of different levels of individual trauma exposure. Second, the sensitivity analysis, which shows that serious property crime is unaffected by presence during a home-country war, provides empirical justification for questioning this variable. Although it is possible, it seems unlikely that only violent crime would be affected by a war in the home country. In past research, one study found a negative correlation between war and 'risk behaviour', which included both non-violent and violent crimes (Rousseau et al., 1999). Moreover, criminological literature identifies common risk factors for both violent and serious property crime (Loeber and Farrington, 2000). At the least, it appears that the effect of war should be in the same direction for both violent and serious property crime. Most likely, presence during a home-country war is spuriously correlated to a factor related to violent crime only. Perhaps migrants from war-torn countries settle, or are placed, in disorganized communities. This could result in the reporting of violence that would probably go unreported in more organized communities (measurement error), or individuals resorting to violence as a means to solve problems. If this is the case, the home country has little real effect on the outcome. Thus, although the first hypothesis is statistically supported in the initial analysis, the result does not seem intuitively accurate and does not withstand the sensitivity analysis. There are also a number of alternative hypotheses that could reasonably explain the finding.

For the second hypothesis, the results of the mean difference test was also supportive. This, however, changed after adding control variables. The addition of control variables appears to have some effect on the history of war variable, while not impacting the effect of presence during a war. Perhaps outcome measurement error or selection-based factors are more likely to be correlated with presence during a war than a history of war. This is 
plausible considering that individuals who have been present in the home country during a war appear more likely to migrate when the war is occurring, often resulting in residential clustering. This is unlikely in the case where there has been only a history of war and the migration occurs on an individual level rather than as mass displacement.

The best-fitting history of war models (Models 3 and 4) show a generally negative relationship between history of war and crime. This contradicts theories on how a history of war affects the likelihood of individual violence, as well as a small body of research on the topic. Since this result is robust across the sensitivity analysis, it seems as though alternative explanations for the history of war are in order. Perhaps a lengthy history of war is a sign of war being used to resolve conflict. After migration to a highly organized society, this tool becomes unnecessary. In this case, the true mechanism at work is being measured indirectly; a direct measure should be sought.

The maximum effect of HDI - a five-fold greater likelihood of violent crime for a randomly chosen immigrant from one of the least developed countries - also seems to be relatively strong. There are a number of possible explanations for the HDI results. For example, acculturative stress (Berry, 1997) may be a form of crime-inducing strain (Agnew, 1992, 2001, 2006) to which immigrants from low-HDI countries may be more susceptible. Or, if low-HDI parents take longer to acculturate than high-HDI parents, their authority may be more easily usurped by their children (Portes and Rumbaut, 2001; Thomas and Znaniecki, 1918). Evidence from Germany (Oberwittler and Höfer, 2005: 488-9), however, indicates that violent crimes committed by migrants from less developed countries may be more likely to be reported to the police than violent crimes committed by migrants from more developed countries. Thus, recording bias may also play some role in the present results.

Disposable income also appears to be important in explaining variation in offending among immigrants. The results indicate that the likelihood of a recorded violent offence is about five times greater for the average immigrant without a disposable income as compared with the average immigrant with a disposable income in the 99th percentile. Recent research from Sweden has indicated that individual economy plays a large role in explaining differences in migrant versus non-migrant offending (Hällsten et al., 2011). This may be true among immigrants as well. The results of the many other covariates also indicate that post-migration factors remain very important for criminal outcomes.

Some have argued that the key to understanding variation in immigrant offending may lie in the different reasons for migration, such as refugee migration or employment migration (Hagan et al., 2008; Tonry, 1997). Unfortunately, information on migration status was unavailable in the data. Yet this may not be a substantial weakness, because looking to documented reasons for migration may be problematic. Castles and Loughna (2003: 3) point out that, regardless of the official migration status, it is often difficult to determine the most important motivations for migration when a migrant comes from a country where conflict and economic difficulties occur simultaneously.

\section{Conclusion}

Though the results of the main analysis were imbalanced - the first hypothesis was supported and the second was not - the overall results generally contradict theories about the effects of war in the home country on criminal outcomes among immigrants. For both 
wars during a migrant's residence and wars in the history of a migrant's home country, it appears that the war variable may be capturing other factors. These factors may be related to either the sending or the receiving country, or a combination thereof. Researchers have already begun considering the context of immigrant reception and could broaden this to include the interplay of the home country. Social disorganization in both the home country and within the receiving country may be one important aspect. Prominent research from the United States on race and crime has shown that neighbourhood disadvantage and socioeconomic inequality play important roles in crime outcomes (Blau and Blau, 1982; Morenoff and Astor, 2006; Sampson et al., 2005). This is also probably true for immigrants and may be amplified when immigrants come from disadvantaged countries. Smoothing the reception and settlement processes to maximize migrant success may reduce these types of problems over time.

One important detail is that over half of the young immigrant males living in Stockholm came from warring countries. Research considering the link between war trauma as experienced by individuals and crime is an important next step for theory and policy; these types of effects were not tested in this research. What this research does indicate is that the relationship between crime and merely coming from a war-torn country does not appear to fit hypothesized causal arguments. Blanket policies seeking either to limit immigration

Appendix I. Model 4: Full model results.

\begin{tabular}{ll}
\hline Variable & Odds ratio (robust standard error) \\
\hline War I & $1.34(0.1615)$ \\
I war & $0.92(0.6900)$ \\
$2-5$ wars & $2.66(1.6965)$ \\
$6+$ wars & $0.1590^{* *}(0.0992)$ \\
HDI at immigration & $0.85^{*}(0.0693)$ \\
Age & $0.98(0.0262)$ \\
Age & $1.00(0.0023)$ \\
Enrolled in pre-high school education & $1.87(2.0167)$ \\
Enrolled in high school & $0.68 * * *(0.0394)$ \\
Enrolled in post-high school education & $0.22^{* * *}(0.0305)$ \\
Enrolled in unemployment education & $3.12^{* * *}(0.8335)$ \\
Enrolled in other education & $0.92(0.2111)$ \\
Son of single mother & $1.24 * *(0.0987)$ \\
Son of single father & $1.40^{* * *}(0.1696)$ \\
Son of one parent in a two-parent home & $1.19(0.1403)$ \\
Son of both parents in a two-parent home & $0.76 * * *(0.0634)$ \\
Son in other type of home & $0.46(0.2345)$ \\
Subject is married & $0.34 * * *(0.0521)$ \\
Subject is in a domestic partnership with children & $0.87(0.1827)$ \\
Subject is single father & $2.22^{*}(0.9181)$ \\
Disposable income (in SEK I0,000) & $0.93^{* * *}(0.0062)$ \\
Years lived in Sweden & $1.04^{* * *}(0.0070)$ \\
QIC & $20,401.905$ \\
$n$ & 134,230 \\
\hline
\end{tabular}

Notes: Country variables are omitted for confidentiality reasons.

One-tailed $p$-values: $* p<.05$; ** $p<.01$; *** $p<.001$. 
or to implement large-scale social programmes based on arguments about higher levels of aggression or cultural dispositions to violence are not supported by this research.

\section{Acknowledgements}

I am grateful for comments from Vanessa Barker, Magnus Bygren, Thomas Frisell and Jerzy Sarnecki on earlier versions of this paper. I would also like to thank the two anonymous reviewers for their valuable comments and suggestions. A version of this paper was presented at the 2011 Stockholm Criminology Symposium.

\section{Notes}

1. As Swedish journalist Per Gudmundson (2011) noted, however, there is not a perfect correlation between coming from a war-torn country and involvement in crime. Many non-war-torn immigrant nativities have lower representation in crime statistics.

2. Those in the top 1 percent of the disposable income distribution were excluded from the analysis.

3. On average, those present during a home-country war have a significantly lower HDI (3.4) at the time of migration than those who were not present during a home-country war (average HDI of $5.2 ; t=247.9828, \mathrm{df}=137,805, p<.000$ ). However, the range of HDI scores for the respective groups overlap almost perfectly. HDI is also negatively correlated with the number of years of war in the country's history $(r=-0.2507, p<.000)$. For the regressions, the variance inflation factor (VIF) values were not worrying.

\section{References}

Agnew R (1992) Foundation for a general strain theory of crime and delinquency. Criminology 30(1): 47-88.

Agnew R (2001) Building on the foundation of general strain theory: Specifying the types of strain most likely to lead to crime and delinquency. Journal of Research in Crime and Delinquency 38(4): 319-361.

Agnew R (2006) Pressured into Crime: An Overview of General Strain Theory. Oxford: Oxford University Press.

Albrecht HJ (1997) Ethnic minorities, crime, and criminal justice in Germany. In: Tonry M (ed.) Ethnicity, Crime, and Immigration: Comparative and Cross-national Perspectives. Chicago: University of Chicago Press, 31-100.

Almqvist K and Brandell-Forsberg M (1997) Refugee children in Sweden: Post-traumatic stress disorder in Iranian preschool children exposed to organized violence. Child Abuse \& Neglect 21(4): 351-366.

Almqvist K and Broberg AG (1999) Mental health and social adjustment in young refugee children 3 1/2 years after their arrival in Sweden. Journal of the American Academy of Child \& Adolescent Psychiatry 38(6): 723-730.

Almqvist K and Hwang P (1999) Iranian refugees in Sweden. Childhood 6(2): 167-188.

Archer D and Gartner R (1976) Violent acts and violent times: A comparative approach to postwar homicide rates. American Sociological Review 41(6): 937-963.

Barenbaum J, Ruchkin V and Schwab-Stone M (2004) The psychosocial aspects of children exposed to war: Practice and policy initiatives. Journal of Child Psychology and Psychiatry 45(1): 41-62.

BBC News (2007) Violent immigrants fuelling crime. 1 May. URL (accessed 5 February 2013): http://news.bbc.co.uk/2/hi/uk_news/england/london/6612817.stm. 
Berry JW (1997) Immigration, acculturation, and adaptation. Applied Psychology 46(1): 5-34.

Black JH (1987) The practice of politics in two settings: Political transferability among recent immigrants to Canada. Canadian Journal of Political Science/Revue canadienne de science politique 20(04): 731-753.

Blau JR and Blau PM (1982) The cost of inequality: Metropolitan structure and violent crime. American Sociological Review 47(1): 114-129.

Byrne JM and Stowell J (2007) Examining the link between institutional and community violence: Toward a new cultural paradigm. Aggression and Violent Behavior 12(5): 552-563.

Cairns E (1996) Children and Political Violence. Oxford: Blackwell.

Castles S and Loughna S (2003) Trends in Asylum Migration to Industrialized Countries: 1990-2001. United Nations University, World Institute for Development Economics Research.

Ekblad SM, Prochazka H and Roth G (2002) Psychological impact of torture: A 3-month follow-up of mass-evacuated Kosovan adults in Sweden. Lessons learnt for prevention. Acta Psychiatrica Scandinavica 106(s412): 30-36.

Farrington DP (1978) The family backgrounds of aggressive youths. In: Hersov LA, Berger M and Shaffer D (eds) Aggression and Antisocial Behavior in Childhood and Adolescence. Oxford: Pergamon, 73-93.

Farrington DP (1991) Childhood aggression and adult violence: Early precursors and later life outcomes. In Pepler DJ and Rubin KH (eds) The Development and Treatment of Childhood Aggression. Hillsdale, NJ: Lawrence Erlbaum, 5-29.

Gleditsch NP, Wallensteen P, Eriksson M, Sollenberg M and Strand H (2002) Armed conflict 1946-2001: A new dataset. Journal of Peace Research 39(5): 615-637.

Gudmundson P (2011) Brottslighet bland invandrare borde oroa alla partier. Svenska Dagbladett, 27 June. URL (accessed 5 February 2013): http://www.svd.se/opinion/ledarsidan/brottslighetbland-invandrare-borde-oroa-alla-partier_6272110.svd.

Hagan J, Levi R and Dinovitzer R (2008) The symbolic violence of the crime-immigration nexus: Migrant mythologies in the Americas. Criminology \& Public Policy 7(1): 95-112.

Harbom L, Strand H and Nygård HM (2009) UCDP/PRIO Armed Conflict Dataset Codebook, Version 4-2009. URL (accessed 5 February 2013): http://www.prio.no/Global/upload/ CSCW/Data/UCDP/2009/Codebook_UCDP_PRIO\%20Armed\%20Conflict\%20Dataset\%20 v4_2009.pdf.

Hastings DA (2009) Filling gaps in the human development index: Findings for Asia and the Pacific. UNESCAP Working Paper, WP/09/02.

Hjern A and Angel B (2000) Organized violence and mental health of refugee children in exile: A six-year follow-up. Acta Paediatrica 89(6): 722-727.

Hjern A, Angel B and Höjer B (1991) Persecution and behavior: A report of refugee children from Chile. Child Abuse \& Neglect 15(3): 239-248.

Hjern A, Angel B and Jeppson O (1998) Political violence, family stress and mental health of refugee children in exile. Scandinavian Journal of Public Health 26(1): 18-25.

Hope C and Edwards R (2008). Knife crime 'fuelled by brutalised refugees' from war-torn regions of Africa. The Telegraph, 5 October. URL (accessed 5 February 2013): http://www.telegraph. co.uk/news/uknews/law-and-order/3140614/Knife-crime-fuelled-by-brutalised-refugeesfrom-war-torn-regions-of-Africa.html.

Hällsten M, Sarnecki J and Szulkin R (2011) Crime as a price of inequality? The delinquency gap between children of immigrants and children of native Swedes. SULCIS Working Paper Series, 2011:1.

King DW, King LA, Foy DW, Keane TM and Fairbank JA (1999) Posttraumatic stress disorder in a national sample of female and male Vietnam veterans: Risk factors, war-zone stressors, and resilience-recovery variables. Journal of Abnormal Psychology 108(1): 164-170. 
Kirk DS and Papachristos AV (2011) Cultural mechanisms and the persistence of neighborhood violence. American Journal of Sociology 116(4): 1190-1233.

Liang KY and Zeger SL (1986) Longitudinal data analysis using generalized linear models. Biometrika 73(1): 13-22.

Loeber R and Farrington DP (2000) Young children who commit crime: Epidemiology, developmental origins, risk factors, early interventions, and policy implications. Development and Psychopathology 12(4): 737-762.

Luckenbill DF and Doyle DP (1989) Structural position and violence: Developing a cultural explanation. Criminology 27(3): 419-436.

Macksoud MS, Dyregrov A and Raundalen M (1993) Traumatic war experiences and their effects on children. In: Wilson JP and Raphael B (eds) International Handbook of Traumatic Stress Syndromes. New York: Plenum, 625-633.

Martens PL (1997) Immigrants, crime, and criminal justice in Sweden. In: Tonry M (ed.) Ethnicity, Crime, and Immigration: Comparative and Cross-national Perspectives. Chicago: University of Chicago Press, 183-256.

Martens PL and Holmberg S (2005) Brottslighet bland personer födda i Sverige och i utlandet. No. 2005:17. National Council for Crime Prevention (Brå).

Miguel E, Saiegh SM and Satyanath S (2008) National cultures and soccer violence. National Bureau of Economic Research Working Paper No. 13968.

Moffitt TE (1993) Adolescence-limited and life-course-persistent antisocial behavior: A developmental taxonomy. Psychological Review 100(4): 674-701.

Morenoff JD and Astor A (2006) Immigrant assimilation and crime: Generational differences in youth violence in Chicago. In: Martinez Jr. R and Valenzuela Jr. A (eds) Immigration and Crime: Race, Ethnicity, and Violence. New York: New York University Press, 36-63.

Nagin DS and Tremblay RE (1999) Trajectories of boys' physical aggression, opposition, and hyperactivity on the path to physically violent and nonviolent juvenile delinquency. Child Development 70(5): 1181-1196.

Oberwittler D and Höfer S (2005) Crime and justice in Germany. European Journal of Criminology 2(4): 465-508.

Orth U and Wieland E (2006) Anger, hostility, and posttraumatic stress disorder in trauma-exposed adults: A meta-analysis. Journal of Consulting and Clinical Psychology 74(4): 698-706.

Pan W (2001) Akaike's information criterion in generalized estimating equations. Biometrics 57(1): 120-125.

Portes A and Rumbaut RG (2001) Legacies: The Story of the Immigrant Second Generation. Berkeley, CA: University of California Press.

Portes A and Zhou M (1993) The new second generation: Segmented assimilation and its variants. The Annals of the American Academy of Political and Social Science 530(1): 74.

Punamäki RL (1996) Can ideological commitment protect children's psychosocial well-being in situations of political violence? Child Development 67(1): 55-69.

Rousseau C, Drapeau A and Platt R (1999) Family trauma and its association with emotional and behavioral problems and social adjustment in adolescent Cambodian refugees. Child Abuse \& Neglect 23(12): 1263-1273.

Sagi-Schwartz A, Seginer R and Abdeen Z (2008) Chronic exposure to catastrophic war experiences and political violence: Links to the well-being of children and their families. International Journal of Behavioral Development 32(4): 357-359.

Sampson RJ and Bean L (2006) Cultural mechanisms and killing fields: A revised theory of community-level racial inequality. In: Peterson RD, Krivo LD and Hagan J (eds) The Many Colors of Crime: Inequalities of Race, Ethnicity, and Crime. New York: New York University Press, $8-36$. 
Sampson RJ and Laub JH (1993) Crime in the Making: Pathways and Turning Points through Life. Cambridge, MA: Harvard University Press.

Sampson RJ, Morenoff JD and Raudenbush S (2005) Social anatomy of racial and ethnic disparities in violence. American Journal of Public Health 95(2): 224-231.

Shaw JA (2003) Children exposed to war/terrorism. Clinical Child \& Family Psychology Review 6(4): 237-246.

Sipes RG (1973) War, sports and aggression: An empirical test of two rival theories. American Anthropologist 75(1): 64-86.

Skardhamar T, Thorsen LR and Henriksen K (2011) Kriminalitet og straff blant innvandrere og øvrig befolkning. No. 21/2011. Statistics Norway.

Swidler A (1986) Culture in action: Symbols and strategies. American Sociological Review 51(2): 273-286.

Thomas WI and Znaniecki F (1918) The Polish Peasant in Europe and America. New York: Knopf.

Tonry M (1997) Ethnicity, crime, and immigration. In: Tonry M (ed.) Ethnicity, Crime, and Immigration: Comparative and Cross-national Perspectives. Chicago: University of Chicago Press, $1-30$.

Tremblay RE, Nagin DS, Séguin JR, Zoccolillo M, Zelazo PD, Boivin M, Pérusse D and Japel $\mathrm{C}$ (2004) Physical aggression during early childhood: Trajectories and predictors. Pediatrics 114(1): e43-e50.

White S, Nevitte N, Blais A, Gidengil E and Fournier P (2008) The political resocialization of immigrants: Resistance or lifelong learning? Political Research Quarterly 61(2): 268-281.

Yule W (2000) Resilience and vulnerability in child survivors of disasters. In: Tizard B and Varma V (eds) Vulnerability and Resilience: A Festschrift for Ann and Alan Clarke. London: Jessica Kingsley, 182-198.

Zeger SL and Liang KY (1986) Longitudinal data analysis for discrete and continuous outcomes. Biometrics 42(1): 121-130. 